\title{
Invasive Species and Natural Function in Ecology
}

\author{
Christopher Hunter Lean ${ }^{1}$
}

\begin{abstract}
If ecological systems are functionally organised, they can possess functions or malfunctions. Natural function would provide justification for conservationists to act for the protection of current ecological arrangements and control the presence of populations that create ecosystem malfunctions. Invasive species are often thought to be malfunctional for ecosystems, so functional arrangement would provide an objective reason for their control. Unfortunately for this prospect, I argue no theory of function, which can support such normative conclusions, can be applied to large scale ecosystems. Instead ecological systems have causal structure, with small clusters of populations achieving functional arrangement. This, however, does not leave us without reason to control invasive species. We can look at the causal arrangement of ecological systems for populations that support ecological features that we should preserve. Populations that play a causal role in reducing biodiversity should be controlled, because biodiversity is a good all prudent agents should want to preserve.
\end{abstract}

1. Department of Philosophy, University of Sydney, A14 Quadrangle, 2006, Australia. For correspondence please send enquiries to christopher.lean@sydney.edu.au. 
'Your heart has great value to your body. No one would argue that point. Does a mosquito population have similar value to a marsh?'

John Kricher, The Balance of Nature: Ecology's Enduring Myth, p .19

\section{Introduction}

There has been a persistent hope that populations in ecological systems have natural normativity, just as organs do in a body. Lungs, hearts, and kidneys have a relatively uncontroversial interpretation as possessing functions and malfunctions, these are normative in the sense that there is something they should be doing. The thought is, if ecological systems are structured so their parts are functional for the whole, they possess a type of natural value. This same natural value would allow us to say: just as the heart is valuable for the body, the mosquito is valuable for the marsh.

Natural normativity could facilitate objective judgements about the role of populations within ecosystems, whether they are functional or malfunctional. Such ascriptions would then act to mediate debates in conservation ethics as to whether populations, which act as parts of a community, aid or hinder a community's interests or perhaps even harm that community. This would provide guidance for many thorny environmental ethics questions. In restoration ecology, for example, populations are often reintroduced into a region given the assumption they will restore an ecological community's functions. An objective account of function would inform when adding a population is warranted. This paper, however, focuses on the question: can function can provide normative guidance as to whether we should control invasive species?

My aims are two-fold. To provide a critical discussion of the theories of ecological function and consider whether invasive species are malfunctional for ecosystems given these theories. Ultimately, I argue for a limited pluralism towards ecological function. Different types of normative function appear in ecological systems, but these are sporadic and rare. Functions in ecology are nearly always dispositional, rather than normative, and so are better understood as descriptions of causal 
structure. However, causal structure can be used to identify features that we should preserve, and this can dictate our actions towards invasive species.

\section{Natural Normativity and Invasion Ecology}

"Invasion ecologists are xenophobes" critics of invasive biology have declared (Raffles 2011; Winograd 2013; Thompson 2014). They argue there is no sound reason to control invasive species or even prefer native species over non-natives. Such preferences are just prejudice, a prejudice not always held by the layperson. For example, one critic notes that crafters in Midwest America prefer the invasive Oriental Bittersweet, as it is better than native species for constructing wreaths and floral arrangements (Sagoff 2005). Locally there is an ongoing debate about the presence of brumbies in the Snowy Mountains, with many viewing these invasive horses as a critical part of Australian culture and folklore. The critics of invasion biology point to the language occasionally used against invasive species (usually in the media) and its similarity to language used in anti-immigration arguments (Pearce 2015). With the implicit assumption being anti-immigration is morally wrong, they accuse invasion biology as being similarly morally suspect. This debate recently moved into the public sphere with popular books and news articles sharing this perspective being targeted to the public (Raffles 2011; Winograd 2013; Thompson 2014; Pearce 2015). Invasion ecologists and wildlife managers worldwide are feeling the pinch of increasing public scrutiny.

Why do critics of invasion biology think there is no real reason to control invasive species? Mark Sagoff (2005) challenges that there are no traits that explain why non-native species would be more "harmful" than natives (p. 219). This, however, requires a prior notion of harm. Once we determine what harms ecological systems, we can see whether it is a good heuristic to prevent the spread and establishment of non-native species. Concepts of harm or malfunction often inform how invasive species ecologists think about the issues (Finnoff et al. 2010; Simberloff et al. 2013). Invasion ecologists defend their position by the effects of invasive species on ecological function 
(Simberloff 2015). Similarly, critics like Mark Davis et al. (2011) state we should rethink invasion ecology and that 'it is time for conservationists to focus much more on the functions of species, and less on their origins' (p. 154).

These notions of harm and function connect with the environmental ethics literature.

Functional organisation is a necessary condition for several different ethical justifications for preserving holistic ecological systems, and as a result, the control of 'malfunctional' species which damage these systems. The connection between 'malfunction' and environmental ethics is particularly clear when ecological communities are treated as if they have health or interests. For example: invasive species can be treated as being analogous to a disease, being malfunctional for 'ecosystem health'. While further factors are needed to establish that a dysfunction is a disease, the existence of malfunction is plausibly part of what it is to be diseased, and whether someone has a disease is normatively relevant to how we should treat them (Wakefield 1992). So, the thought is, if there is an objective sense in which populations, such as invasive species, cause ecosystems to act in a malfunctional or diseased manner, then it is normatively relevant to how we should respond. J. Baird Callicott (1995) defends an ecosystem health realist position, where ecosystems are to be considered "nested sets of linked process-functions with temporal boundaries" and, therefore, health "is an objective condition of ecosystems" (p. 345). There is, in this view, a real sense in which ecological health can be improved or diminished.

Similarly, there has been a revival of biocentrism, the thesis that "living beings have a good of their own because they are end-directed or teleological systems" (Holm 2017, p. 1075). This is used to argue for non-anthropocentric reasons to preserve the environment as it contains entities with their own interests, who we should not impede (Taylor 1989; Varner 1998; Sandler 2007). Biocentrism usually takes organisms to be the right entities for ethical consideration, a position called teleological individualism. Recently, John Basl (2017) has argued against teleological individualism and that biological collectives, such as ecological systems, should be considered within the ethical scope of biocentrists ethical consideration (without himself being a biocentrist) (also see McShane 2014). Holmes Rolston III argues for biocentrism, claiming organisms are "spontaneous cybernetic 
system, self-maintaining with a control center, sustaining and reproducing itself on the basis of information" with "a goal" which could provide a "measure of success". This gives them their own self-authored value as they are "evaluative systems" (Rolston III 1988, p. 99). On such biocentrist views we should promote and preserve ecological communities' interests if they similarly satisfy these conditions. Philosophers like Lawrence Johnson (1991) argue this case, aiming to establish that 'ecosystems have morally significant interests' and 'denying that their interests are merely the aggregated interest of individual organisms' (p. 148). Within a biocentrist framework, if invasive species impede an ecological community's interests, we should aid the ecological community by controlling these populations.

The teleological arrangement of ecological systems is only a necessary condition for ethical duties within these theories. The environmental ethicist must display both that ecological systems have natural normativity and that natural normativity is ethically significant. Natural function is often of little ethical consequence, even in organisms that are undoubtable highly functionally organised. We kill other organisms, whether plant, animal, or bacteria, for all sorts of reasons with little ethical squeamishness. Even when it comes to human health and disease there are some who argue that there is no connection between health and natural function (Glackin 2010). This may be an insurmountable problem for environmental ethics, but it is not the problem I address. I focus on the prior question of whether ecological systems are functionally organised. This matters both as a necessary condition for these ethical positions and as means to explicate the functional language used by ecologists in debate over invasive species.

\section{Naturalized Function in the Sciences}

There is a rich and comprehensive philosophical literature attempting to naturalize function. It takes teleological statements such as the "heart is for pumping blood" and redescribes them to capture the goal directed nature of such statements within a scientific worldview. The goal directed aspect of 
teleological statements allows for normative inferences; if a heart is not pumping blood then it is doing something wrong, in some sense. Prominent normative theories of function include Selected Effects functions and Organisational functions. The Australian Melaleuca is invasive in the Florida everglades ecosystem. Melaleuca's dry out their local area through high water consumption and exclude other plants through promoting fires, to which they are highly adapted. For the Melaleuca to cause the everglades to be malfunctional we need a notion of function that gives us objective malfunction, not just a mirror to our preferences for particular biological systems. For a population to have one of these normative functions it must possess that function even when it is not preforming it. Otherwise, these 'functional' relations are equivalent to causal relations. Causal theories of function dictate that we can only make statements about whether a functional effect is present or not. We may value the existence of this function or disvalue it, but the normativity involved only comes from us. So, there would be no sense in which the Melaleuca causes a malfunction, it just stopped the causal relations which previously existed in the everglades and we as agents disvalue this.

Before I place all the vying accounts of function on the table, both normative and dispositional, I will dismiss one possibility: there is a single right account of function for ecology. Many have argued for the right theory of ecological function to the exclusion of all others in the wake of Maclaurin and Sterelny's (2008) Causal Role community functions, with Nunes-Neto et al. (2014) exclusively defending Organisational functions for ecological community's and Dussault \& Bouchard (2017) arguing for the superiority of Persistence functions. Monistic stances towards function are misguided (Godfrey-Smith 1993; Griffiths 1993; Amundson and Lauder 1994; Garson 2017b). All these different theories of function appear to plausibly apply to most organisms, but I argue this is not the case in their general application to ecological systems. While organisms - the paradigm cases of functional entities - are like ecological communities in that they are diverse in structure, composition, and degrees of integration, they are indisputably more stable and tightly integrated than ecological systems (Clarke 2011; Godfrey-Smith 2012; Lean 2018). That an organism-like entity behaves like an ecological system has been used as a criterion for it not being an organism (Skillings 2016). As such 
organisms are used as an implicit, and sometimes explicit, contrast class to ecological systems, but the focus of discussion is on the qualities of ecological systems.

In the following sections, I will outline the extent to which ecological systems satisfy the conditions for the four different classes of ecological function described below: Selected Effects Functions, Persistence Functions, Causal Roles Functions, and Organizational Functions. For each of these I outline and discuss their application to ecology.

\subsection{Selected Effects Functions.}

In organismal biology the most prominent theory of function is the Selected Effects (SE) function. The SE function of a trait, or part, of an organism is the effect(s) that trait has which were selected for in previous generations (Neander 1983; Millikan 1984). To use the canonical example, the function of the heart in an organism is to pump blood, which in turn helps the organism stay alive and produce another organism which has a functioning heart. Paradigm cases of SE functions are the roles of individuated sub-systems in organisms. The history of selection on organisms provides a privileged and non-arbitrary means to individuate these biological systems and identify their biologically significant causal effects. This allows for the ascription of normativity to traits and the ability to discern between accidental and functional traits. There are many different causal effects organismal sub-systems can have; for example, a beating heart makes a phump-whump sound, which is not functional for that organism as it has not been subject to natural selection. "Accidental", or fortuitous new arrangements of a trait, confer an advantage but are not functional. Both fortunate accidents and malfunctions are assessed against the historically selected role of the trait. The token trait is assessed against the selected trait type, which allows for the normative dimension of functions to be identified. The functional trait must act in a historically appropriate way to be functional.

Natural selection can occur on multiple levels of biological organization and whatever level selection occurs at can bear SE functional traits (Godfrey-Smith 1993). If ecological systems are 
subject to natural selection, then they will possess SE functions ${ }^{1}$. These ecological systems will need to be "Darwinian individuals" (Godfrey-Smith 2009), they cannot be any mereological arrangement.

The overall community composition must respond to natural selection and form stable lineages, reproducing over time. But as Maclaurin and Sterelny (2008) argue, ecological systems do not form clear lineages or form Darwinian populations. Populations in a community are not tightly causally coupled over extended periods compared to organisms, which have more causally integrated. An ecological lineage, multiple populations with consistent causal relationships, being reproduced over multiple generations is implausible. The constant rearrangement of the relationships in ecological systems obstructs the formation of the long-term relationships required for lineage formation. Even when populations cohabitate an area, they are unlikely to have co-evolutionary relationships (Sagoff 2019).

Given this, there is a steep hill to climb to establish that there are ecological SE functions. But in a limited set of cases, there are plausibly ecological Darwinian populations. Ecological lineages are not ubiquitous, but they can exist in the small scale with only a few populations. The most common ecological lineages are cases of reciprocal specialisation, in which populations co-evolve to form mutualistic relationships. A famous example is the Malagasy Orchid, which Charles Darwin observed with its foot-long nectary and hypothesized that there must be a moth with a foot-long proboscis. Four decades later Morgan's Sphinx Moth was discovered with a foot-long proboscis (Kritsky 1991). These two species have unique morphologies, which mean they depend on each other for survival. They, as a pair, form an ecological lineage, with two populations being recreated in the same causal relationship over time. These populations could be recreated in new habitats forming something

\footnotetext{
${ }^{1}$ A fascinating new development is Roberta Millstein's (forthcoming) thesis that populations have ecological selected effects functions even if communities do not undergo natural selection. Coevolution provides an ecological function to an organism, it is selected to perform as a 'parasite' or 'detritivore' for only a few specific species, which provides the 'ecological role' it plays in the larger ecological system it belongs to. To my understanding, in this case Millstein is arguing that there is 'selection for' ecological functions without 'selection of' ecosystems. Such functional statements may be possible, but as of yet I cannot see how to connect these co-evolutionary roles with the larger ecological community they sit within; especially when these populations are taken outside of their historic ranges. I look forward to further developments of this idea.
} 
weakly analogous to reproduction ${ }^{2}$. Each of them would possess a corresponding SE function for the maintenance of this two-population ecological unit. This reciprocal relationship maintains the higherlevel ecological lineage as both need to maintain their causal relationship due to their fitness dependency on the other. This strong dependency makes it possible that they as a unit compete with other populations for resources. Thus, I consider reciprocal mutualistic relationships as plausibly SE functional.

Reciprocal adaptations are required for SE functions; asymmetrical adaptations are not strong enough to create an entity subject to natural selection. The plants in an ecological community will be adapted to the provision of sunlight but the sun is not dependent on those plants. Equally, if a tree relies on an insect pollinator but that pollinator does not rely on it, we have an asymmetry. Natural selection is occurring on the tree, not the whole community of tree and pollinator. Most ecological networks are asymmetrical (Rezende et al. 2007; Bastolla et al. 2009). The populations within these networks will not have reciprocal adaptations so do not belong to a single selectively sculpted system.

Ecological systems with SE function will be severely limited. They will only have very few populations, who necessarily cohabitate, and border on, or are, symbiotic. Examples will include, holobionts and lichens; but even these may not constitute units of selection! (Booth 2014; Skillings 2016). Once you expand past such intimate co-evolutionary relationships, the contingencies of defection or disappearance become too great. If invasive species disrupt these reciprocal relations, they will be 'malfunctional'. Large scale communities, therefore, do not possess malfunctions. Further, without a history of co-evolution invasive species cannot form new functions in novel ecosystem. Given these limitations classic SE functions cannot provide serious guidance in ecological policy.

${ }^{2}$ This point is up for debate, it depends on what is accepted as the reproduction of a set of lineages. Different theories of reproduction are more or less stringent (See Griesemer 2005; Godfrey-Smith 2009). 


\subsection{Persistence Functions}

Garson (2011; 2017a) and Dussault and Bouchard (2017), in response to the limitations of SE functions, expand what counts as selection. They defend two different theories of function through differential persistence or retention ${ }^{3}$. These theories avoid the need for reproduction or lineage formation, so they are thought to be more applicable to ecological systems. Dussault and Bouchard (2017) state an ecosystem has a function if:

'The function of $\mathrm{x}$ in an ecosystem $\mathrm{E}$ is to $\mathrm{F}$ if, and only if, $\mathrm{x}$ is capable to doing $\mathrm{F}$ and $\mathrm{x}$ 's capacity to $\mathrm{F}$ contributes to $\mathrm{E}$ 's propensity to persist'

Dussault and Bouchard 2017, p. 1122

The differential persistence theories of function, as it currently stands, cannot be applied to ecological systems. This project requires a principled and objective distinction between the persistence of an ecological system and its replacement by a new system. The authors of persistence theories of function, as of yet, have not provided the resources to be able to apply their theory and this will require redress. This is in contrast with the varied attempts to provide principled theories of reproduction and lineage formation, which are necessary to identify SE functions (Dawkins 1982; Griesemer 2005; Godfrey-Smith 2009). Reproduction and the formation of lineage provide identity conditions for SE functional systems. Without similar identity conditions, persistence theories of function cannot be applied, as of yet.

Identity conditions are difficult to provide for ecological systems. If communities are idiosyncratic, there is no reference class of community types to identify whether a trait has contributed to differential persistence. For example; to identify whether an increase in soil salinity allows for the differential persistence of dry sclerophyll forests, we need to look at one dry sclerophyll forest with high salinity and compare it to another dry sclerophyll forest with low salinity (which then

\footnotetext{
${ }^{3}$ Differential retention I find more plausible than propensity to persist, but I do not have the space to expand on why, so I will consider these accounts together.
} 
does not persist $)^{4}$. For the persistence theory of function to be fruitfully applied, it is not enough for a dry sclerophyll forest to continue in roughly the same region. This forest must be the same forest.

Persistence function proponents must provide identity conditions for ecological communities to determine if the system has persisted through internal change. Continued individuality of an ecological system requires a notion of growth or reproduction or internal cohesion (where internal cohesion is not relying on persistence and therefore circular). This is difficult as ecological communities do not appear to have any unified identity conditions, there is nothing that appears to unify ecological kinds (for more on ecological identity see Jax et al. 1998; Grimm 1998; Jax 2006). Without the identity conditions for community persistence the relevant contrast class for whether a trait allowed the community to persist or not cannot be found. For example, to identify if a dry sclerophyll forest has persisted due to an increase in soil salinity over a forest in low salinity environment, we must be able to answer two questions of identity. Are these two dry sclerophyll forests the same and did the dry sclerophyll forest that "persisted" retained its identity over time?

This is a problem, as dry sclerophyll forests are unique; the Office of Environment and Heritage in New South Wales describe ten different dry sclerophyll forests such as the HunterMacleay dry sclerophyll forest, which is dominated by spotted gum, and Upper Riverina dry sclerophyll forest, which is dominated by box gum ${ }^{5}$. As we go to finer and finer grains, there will be different species and proportions of species and abiotic facts and causal arrangements of species in each of these regions. There is, therefore, no relevant contrast class to identify whether a trait makes a difference to persistence ${ }^{6}$. This differs from organisms where we have a well-established contrast

\footnotetext{
${ }^{4}$ We would further need to identify whether the salt makes an actual causal difference, or whether it is some other causal factor, like rainfall or the addition of a population of wedgetail eagles. This is a serious epistemic barrier.

${ }^{5} \mathrm{http}$ ://www.environment.nsw.gov.au/threatenedSpeciesApp/VegFormation.aspx?formationName=Dr $\mathrm{y}+$ sclerophyll+forests $+($ shrub\%2Fgrass + sub-formation $)$ Accessed 14.08.2019

${ }^{6}$ One option is we could indulge in some serious metaphysics and attempt to look at the ecosystem's counterpart in the nearest possible world without that trait (Lewis 1971). I doubt the proponent of this version of naturalised function will find this desirable. Even if they do, there are issues with using such possible world semantics for identity (Mackie \& Jago 2017).
} 
class, the other organisms within that species. These provide naturally occurring replications which help identify whether a trait aided in the persistence of that organism. While organismal identity conditions are difficult, we at least have good principles for which entities we should compare when we try and establish whether an individual persisted.

Dussault and Bouchard (2017) realize this is a problem, admitting the 'Heraclitean problem of an entity's sameness through change, is that of the ecosystem' (p. 24). They concede attempts to define ecological identity often result in large disjuncts of different criteria (e.g. Jax et al. 1998). To address this problem, they posit that all these different kinds exist, through John Dupré's 'promiscuous realism', in which any mereological sum is a kind, if it is useful for an agent (Dupré 1993). Under Dupré's theory any patch of an ecosystem will consist of many differing overlapping ecological systems with different identity conditions. This is problematic for the persistence theory of function. Any region will have countless "real" ecological systems, some of which will persist under a given change, like invasion, and others that will not. If there are multiple different functional ecological kinds within an area, Dussault and Bouchard (2017) must be able to ascribe consistent propensities for persistence to each of these kinds. These spatially co-existing propensities will need to translate across the different co-extensive ecosystems; they cannot be radically inconsistent. With so many different ecological kinds, we will be given an immense disjunction of propensities, each representing a different ecosystem present within that patch of land. This leads them to admit 'persistence may remain a non-operational concept until some identity conditions are specified' (Dussault \& Bouchard, p. 1139). While they can leave this as future work to be done, as it stands, they cannot determine what has a function.

The resources necessary to establish the continuity of a community, given a function part, are required for displaying the co-dependency between functional parts and the larger community these parts functions for. Otherwise, it is unclear why persisting entities should be described as normatively functional. Theories of natural function naturalise the teleology of a system's parts via the role these parts play in the larger system they belong to, but the larger system is usually understood to contribute to the existence of the system's parts as well. In contrast, ecosystem traits 
which aid the persistence of the ecosystem do not explain how the system influences the ecosystem traits' existence. This is because persistence does not require a feedback loop from the effect of the trait on the larger system back to the continued existence of the trait ${ }^{7}$. The microclimate which aids the persistence of an ecological community does not necessarily explain the microclimate. Therefore, it is unclear to me what we gain from this broadening of function. Persistence function are not without potential to explain some phenomena, but as they stand, they require significantly more development.

\subsection{Organizational Functions}

A relatively new theory of natural functions is the Organizational $(\mathrm{O})$ function, which represent normativity in natural systems without reference to natural selection (Mossio et al. 2009). O functions require that systems be structured for self-maintenance: a closed differentiated selfmaintaining organisation. $\mathrm{O}$ function proponents equate normativity with self-maintenance, as it is for the good of the system. This theory of function has been applied up and down the biological hierarchy, describing functional composition in individual organisms and their functionally composed sub-systems (Saborido et al. 2011).

The formalized theory of $\mathrm{O}$ function states, a trait $\mathrm{T}$ has a function in the organization $\mathrm{O}$ of a system $S$ if and only if:

$\mathrm{C} 1$ : $\mathrm{T}$ contributes to the maintenance of organization $\mathrm{O}$ of $\mathrm{S}$

$\mathrm{C} 2$ : $\mathrm{T}$ is produced and maintained under some constraints exerted by $\mathrm{O}$

C3: S is organizationally differentiated (Mossio et al. 2009, p. 828).

\footnotetext{
${ }^{7}$ Thanks to Kim Sterelny for pressing this point.
} 
$\mathrm{C} 1$ and $\mathrm{C} 2$ are described as combining to identify a system with organizational closure ${ }^{8}$. This is when $\mathrm{T}$ maintains $\mathrm{O}$ and $\mathrm{O}$ maintains T's presence. $\mathrm{C} 3$ articulates organizational differentiation: $\mathrm{T}$ must be a sub-part of the overall system, with a unique causal profile, rather than the whole system. In the case of the heart, the heart is a differentiated subpart of the body, it maintains the body and the body constrains and maintains the actions of the heart. Co-dependency between parts and the system provides natural normativity.

Nunes-Neto et al. (2014) argue ecological compositions are O-functional with the example of a resource cycle formed within a tropical bromeliad. The spiders that inhabit the bromeliad are functional, as their consumption of small insects drops nitrogen into the pool of water formed at the bromeliad's base. The nitrogen sustains the bromeliad and the bromeliad in turn provides a habitat for the spiders. This system is centred on an isolated individual plant and the way this plant provides a habitat for the species that maintain it. This indicates that the system has organizational closure. Organizational differentiation is satisfied as each population acts uniquely in the ecosystem's causal structure. Finally, the resource cycling sustains all the populations within this system, meeting the self-maintenance condition.

Even if the bromeliad system is genuinely self-maintaining, such cases are the exception. Notice this system is physically small, only occupying several metres cubed, and its causal actors are few and well-defined, only comprising of insects, spiders, and a plant. This limited size and strong identity conditions allow $\mathrm{O}$ functions to describe self-maintenance over time and avoid the issues of persistence functions. $\mathrm{O}$ functions are less likely to apply to ecological systems as they scale up in their size, complexity, and openness. Invasive species could disrupt O-functions when they interact with them, but this is inconsequential, as O-functions are rare and exist on significantly different scales to invasive populations.

\footnotetext{
${ }^{8}$ Recently, C2 was reformulated by the main proponents of Organisational functions (Moreno and Mossio 2015). I am, however, responding to the version of Organisational functions found within Nunes-Neto et al. (2014). Thanks to a reviewer for drawing my attention to this.
} 
Why are $\mathrm{O}$ functions rare in ecology? We must look at the conditions for $\mathrm{O}$ functions separately: organisational differentiation and organisational closure. Both are problematic for a general application of $\mathrm{O}$ functions to large scale communities. Organisational differentiation requires the functional trait be a defined subpart of the system with a distinct causal profile. While it is possible to do this, as in the case of the bromeliad, much of ecological phenomena does not involve easily differentiated features. Causal closure is even more difficult to satisfy as ecological systems are rarely, if ever, closed systems.

Organisational differentiation requires different distinguishable populations or abiotic resources to form parts of a community. Just like in the case of persistence function, we must be able to define and identify an ecological system and its parts over time. Topography and geology will produce some abiotic bound sub-systems, but demarcating autonomous abiotic ecological systems is difficult (Odenbaugh 2010; Post et al. 2007). Text-book depictions of nutrient cycles involve incredible amounts of idealization, cramming diffuse multi-factor interactions into a single node, to the extent that it is hard to see what they represent. These parts must also provide distinct causal profiles. Abiotic units are spatially diffuse, exerting causal control in many ways across the entire system at once. Rain can cause plants to grow, fungi to reproduce, animals to disperse, soil to be eroded, and insects to drown; each has an impact on the composition of the ecosystem ${ }^{9}$. Equally, populations maintain ecosystems through aggregational properties rather than distinguishable causal profiles. Many of the proposed links between stability and diversity go via the aggregation of many different populations rather than differentiated sub-parts playing roles. (Sterelny 2005; Dussault and Bouchard 2017).

Organisational closure is even more problematic for applying organisational functions to ecosystems. Equating ecological systems with closed self-maintaining unit requires a strong commitment to equilibrium ecology. Equilibrium ecology was prominent through the middle of the $20^{\text {th }}$ century and sought to establish that populations within a community regulate each other's

\footnotetext{
${ }^{9}$ For more arguments against water cycles being teleological see: Mossio and Bich 2017, p. 1100.
} 
abundance (Pimm 1991; Cooper 2003). A classic example is the oscillation of predator and prey populations as described in the Lotka-Volterra model. Population interactions were believed to stabilize the community composition. When these stabilising interactions are coupled with stable population ranges they result in bound self-maintaining ecological systems.

Equilibrium ecology has experienced extensive criticism through its history (Cooper 2003, p. 46-55). The contrary view, non-equilibrium ecology, argues that communities are casually open collections of species. Local community composition is the product of path-dependent historical processes and the random dispersal of populations from other local communities. Local species presence or absences are a patchwork of dispersal and local population collapse (Hubbell 2001, p. 89). If this picture is correct ecological communities are not closed systems; they are the product of many populations moving around larger biogeographic regions (Ricklefs 2005; Lean and Sterelny 2016). Due to the large turnover of species within a local area, we will see a change in not just the populations playing a functional role but also the overall causal structure of the system. This will change the organisation of the system so there is no longer the functional maintenance of the ecological system by a population. It is an open empirical question as to which ecological systems are subject to non-equilibrium dynamics and which are in equilibrium. Some evidence suggests many arid and tropical rainforests exist well away from equilibrium (Sullivan 1996; Hubbell 2001; Ricklefs 2005).

O functions will occur in some ecological systems. Generally, they will be small ecological systems, with just a couple of populations in close physical proximity. Invasive species, when they invade ecosystems, can disrupt whatever O functional systems are present. If the invaders outcompete the native species within their $\mathrm{O}$ functional communities, invasion will result in the destruction of the O function. In such cases, we can state that invasive species are malfunctional for these systems. It is possible for the invasive species to form an ecological $\mathrm{O}$ function, just unlikely due to the need for pre-existing functional correspondence between the invasive population and the native assemblage. So, O functional novel ecosystems are possible but rarer and smaller than some may expect. The disruption or formation of $\mathrm{O}$ functions will, just like SE functions, be uncommon. 


\subsection{Causal Role Functions.}

The main competitor to SE functions is the Causal Role (CR) function (Cummins 1975). This type of function is explanatory; it explains how a part contributes to a system's capacity, whatever that capacity may be. Within this theory, the function of system sub-part is the systemic capacities, and structure organisation, of that sub-part which explain the capacities of the system it belongs to. As it is an explanatory relation, it can only describe the presence or absence of a function, not whether the trait is malfunctional or accidental. It, therefore, has no normative component; there is no way a CR functional system "should" be acting. To have a CR function an ecosystem only needs to be causally or constitutively continuous, and it needs to possess a capacity we wish to explain given its parts. This theory of function has been applied to ecological systems (Sterelny 2006; Maclaurin \& Sterelny 2008; Odenbaugh 2010).

A suitable example of a CR function is Robert Paine's (1966) experiment of removing the starfish Pisaster from intertidal rock pools. Through repeated intervention, he identified that Pisaster played a distinct, stable, and unique role in that system. The community described by Paine is built from the communities causal relations indexed to a single population: Pisaster. This food web is called a sink food web as it is indexed to a predator (the energetic sink) to which the rest of the populations are related. Pisaster predates on all the other populations in the community but prefers the California Mussel (Mytilus). When Pisaster is removed from the system, the Mussel population rapidly increases, spatially excluding all the other species. This causes a collapse in the species diversity within the system (Paine 1974). 


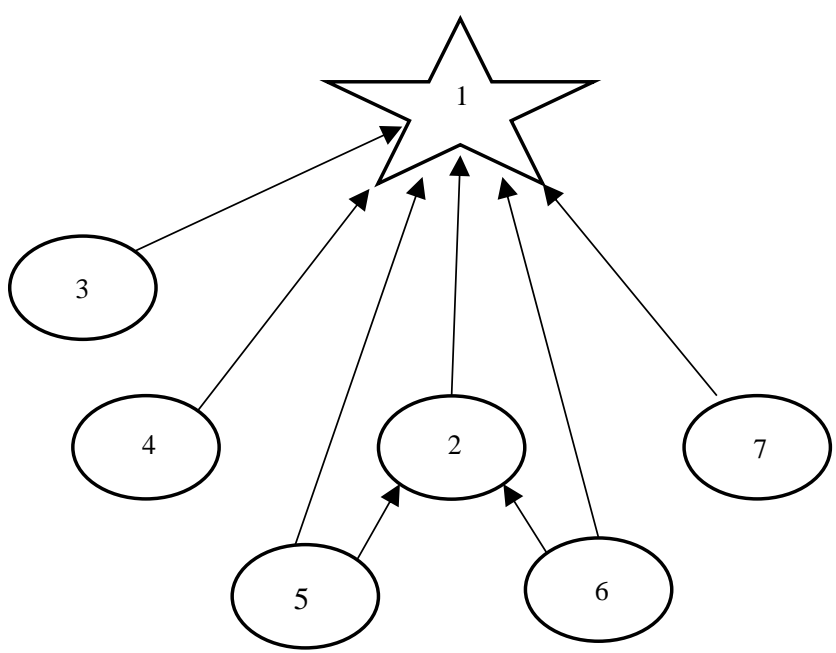

5.2. The intertidal ecological community. Arrows indicate the flow of energy. The different populations are: 1) Pisaster 2) Thais 3) Chitons 4) Limpets 5) Bivalves (including Mytilus) 6) Acorn Barnacles 7) Mitella. As the apex predator, Pisaster suppresses strong competitor populations in the community increasing diversity.

The Pisaster population in Paine's community plays a distinct unique role in the system. But what is the role for? We could describe the function as being for the suppression of the mussel population but that is not interesting for understanding the overall capacities of that ecological community. By suppressing the mussel population, Pisaster maintains the community's species composition, the population network structure, and species richness. Counterfactually, all these different ecosystem properties are not identical; we could have variation in one and not the others. All of them are interesting, as these dynamics are explanatorily relevant to different scientific hypotheses, and we could aim to explain any of them using the CR function framework.

The flexibility of this theory allows it to explain any ecological system's capacity, provided there are constitutive and causal relations in that community. As the system and capacity of interest is explicitly defined by the researcher, $\mathrm{CR}$ functions do not suffer from the issues of identity that undermine persistence functions. But this flexibility to explain capacities has been seen as a weakness by Nunes-Neto et al. (2014) and Dussault and Bouchard (2017). They correctly identify that invasive species can be functional for the collapse or fragmentation of an ecological system. For example, the feral Goat in Australia removes Australian flora and fauna as it overgrazes Australian plants and outcompetes yellow-footed rock wallabies for rock shelters. The Goats then bring in other invasive 
plants (weeds) into the areas through seeds carried in their dung, which can quickly grow in the soil Goat's hooves overturn ${ }^{10}$. Goats have a systemic set of causal relationships to both the native habitat and other invasive species. This creates a novel ecosystem, comprising of weeds and the native plants which survive herbivory. Goats do not contribute to the survival of the previously present ecological system; they promote their own novel ecosystem.

The conclusion that invasives, like Goats, causally support their own novel ecological system, and this does not count as a malfunction, has led some to argue that CR function's apply functions to causal relations which are counterintuitive to the research aims of community ecology (Dussault \& Bouchard 2017, p. 1120). That is, because invasive species can be CR 'functional', the use of CR functions 'misdiagnose' malfunctional relationships in ecology. Assuming that invasives are malfunctional is a mistake derived from overinterpreting the normative language used to describe invasive species (Chew \& Laubichler 2003; Brown \& Sax 2004). As this theory of function is explanatory, we may want to know the causal capacities of invasive species in ecological systems so that we may understand what ecosystem features they diminish or promote. We can use functional analysis to identify the effects of invasive species, but functional analysis will not tell us whether those effects are desirable or not.

\section{The Role of 'Function' in Conservation}

Ecological science has often drifted between two extremes (Cooper 2003; Eliot 2011). On one extreme, ecological systems are treated as mere collections of populations, largely independent of each other (Gleason 1926). On the other, ecological systems are analogous to organisms, possessing functional organisation that maintains mature organism-like individuals (Clements 1916). If ecological systems are organism-like they will have functions from which conclusive statements

${ }^{10}$ Australian Government Invasive Species Fact Sheet https://www.environment.gov.au/biodiversity/invasive-species/publications/factsheet-feral-goatcapra-hircus Accessed 14.08.2019 
about what is normatively functional or malfunctional can be made. The picture I have presented sits between the extremes. Ecological systems have complex causal relationships, but they are rarely selfmaintaining or evolutionary entities (Lean 2018). The large-scale communities which feature in conservation decision making will not possess normative functions. Therefore, invasive species are not malfunctional for ecological communities in the same manner as infectious diseases are for the organisms they infect.

This, however, is no great loss. Founding conservation on teleology is a misstep. The teleological arrangement of ecological systems is extremely spotty. There are little blips of teleological arrangement, but these are not strong enough to support an entire conservation ethic. Teleological composition does not include much of the phenomena conservation aims to protect, specifically, biology beyond organisms. For this reason, focusing on interests or welfare is not the right way to do conservation (Basl 2019). The most teleologically arranged entities will always be individual organisms not populations or ecosystems. Any calculus that weighs overall welfare, as the means of determining their overall value, will describe individual organisms as the most deserving. Further, the realization the biological individuality come in degrees has led to philosophers considering the extent to which organisms are functionally integrated (Clarke 2011; Godfrey-Smith 2012; Skillings 2016). Organisms could be understood as having different potentials for experiencing degrees of welfare according to the degree of their functional arrangement.

The reliance on functional organization to ground ethical consideration ignores the targets of conservation which are above the level of individual organisms, and it does not capture the uniqueness of organisms past their functional integration. This I would categorize as a poor conceptual analysis of our ethical relationship to nature, as it misses the features conservationists aim to preserve (Soulé 1985). A teleological focus in conservation will yield counterintuitive results. It is widely known that welfare of organisms often trades-off against conservation interests (Sagoff 1984). If we only want to promote functional entities, we would prioritise well organised organisms creating a 'functional chauvinism' like the 'sentience chauvinism' Peter Singer's animal liberationist ethical theory is often accused of (Colyvan et al. 2009; Singer 1975). Given there is more to conservation 
than functionally integrated organisms, I think that we should look elsewhere for our ethical justification.

Despite the lack of teleology in ecological systems, there are resources available in the function literature for conservation. CR functions inform us how a system works and this in turn will constrain what we can do. By deploying CR functional analysis, we can identify what supports the ecological features that we do, or should want to, protect. These could be features of the environment which have moral utility or preference. While this does not offer us a non-anthropocentric justification for intervening on ecological communities, it does offer a way of identifying which populations make a disproportionate impact on the community. Large impacts will affect more individual components of that system, which people may have an interest in preserving. If these large impacts negatively influence many of these individual components people value, then we should act to stop them. With such tools in hand we can better compare the impact of conservation decisions on the environmental feature of interest to opposing parties. Different modes of injecting normativity into the causal nodes of ecosystem structure, the individual populations that form the ecological community's causal network, will play a role in deciding whether we should control invasive species (Lean 2018).

To display the utility of CR functions in conservation, I present one way we can introduce normativity into this causal structure, which provides guidance for how we should act towards invasive species. Populations that are CR functional for biodiversity should be supported and invasive species which act to diminish biodiversity should be controlled. Biodiversity is a feature most conservationists aim to preserve and, insofar as we should preserve biodiversity, we should support invasive species control as invasive species reduce global biodiversity (Clavero \& García-Berthou 2005). This is not the only way to introduce features of normative worth into this causal analysis, other principles could be used to identify features of value to humanity. For example: we may want to preserve areas which provide ecosystem services, or goods of immediate economic value. Immediate economic value is a common currency and may allow for some leeway in complex negotiations. I focus on biodiversity because, as I explain in the next section, there are multiple intersecting reasons to preserves it and there are indisputable cases where it is negatively affected by invasive species. 


\section{Functions for Biodiversity}

There are multiple intersecting motivations for preserving biodiversity, which provide a strong case for controlling invasive species when they reduce biodiversity. Biodiversity preservation is a common aim for much of conservation (Soulé 1985; Sarkar 2012; Lean 2017). Biodiversity is often touted as promoting ecosystem services. Within this literature, biodiversity is CR functional for ecosystem services as it is described as causing features of economic utility ${ }^{11}$ (e.g. Mace et al. 2012). But unique to biodiversity preservation is that it promotes option value (Faith 1992; Nehring \& Puppe 2002; Maclaurin \& Sterelny 2008). Preserving unique species provides different options in that their unique capacities are or could be of value. Option value is a type of prudential reasoning; we wish to keep resources available for future use. Insofar as we should act prudentially, or it is rational to act prudentially, we should preserve option value. There is a question of how much we should invest in options, as opposed to immediate preferences. Such questions will require decision-making under risk, and agents' decisions about how much risk they wish to take. Given most agents will reasonably view alleviating risk and preserving opportunities as an important motivator, they will want to promote biodiversity.

Biodiversity thus creates conservation priorities. We can identify the ecological features that maintain or promote these biodiverse populations using the CR function framework. If invasive species threaten populations that are CR functional for biodiversity, then we have reason to control them. This framework mirrors the way conservationists often discuss the problem of invasive species. Not all exotic species are controlled; species that are described as invasive are done so under the assumption they have a large impact on other populations or economic services (see Young and Larson 2011). It is the invasive populations that actively reduce the unique local biodiversity that most conservations aim to control, and the CR functional framework can act to clarify these

\footnotetext{
${ }^{11}$ Thanks to David Frank for this point.
} 
relationships. An example of the relationship between regional biodiversity and invasive species can be found in Southern Queensland.

The Southern Cassowary is a species of $1.8 \mathrm{~m}$ tall birds found throughout Southern Queensland. These large and dangerous birds are in themselves quite evolutionarily distinct and contribute to biodiversity as their own population's self-maintenance reflexively preserves biodiversity. Cassowaries play a further critical role in preserving more biodiversity within the rainforests they inhabit. They are megafaunal dispersers, or large animals that stand in a mutualistic relationship with plant species (Guimarães Jr et al. 2008; Janzen \& Martin 1982). Many plants have large seeds and fruit made for megafauna to consume, transport, and fertilize. With the spread of humans, who excel at hunting megafauna, there has been a gigantic diminution of megafauna worldwide. Some mutualistic plants, like the avocado, have avoided extinction by being appealing to humans, but many plants have become extinct through the knock-on effects of losing their dispersers.

In the Cape York Peninsula rainforest, the Cassowary acts as the only local megafaunal disperser, dispersing the seeds of 78 species of plant (Stocker \& Irvine 1983). These seeds are of unique and distinct lineages of plants that contribute to biodiversity. Cassowaries make a distinct and persistent contribution to the maintenance of these systems as one of the world's rare remaining avian megafaunal dispersers. To preserve the plants that comprise the rainforest we need to preserve the Cassowary population on which they all causally depend. The unique contribution of Cassowaries to biodiversity justifies the control of invasive populations which threaten their existence. Feral pigs negatively affect Cassowary populations (Chrome \& Moore 1990). Pigs destroy cassowary nests, eating both eggs and chicks. By consuming ground fruit, they also compete with Cassowaries for food. Pigs make a stable casual contribution to the reduction of biodiversity within the North-Eastern Queensland rainforests.

Using CR functions, we can move from a system capacity, the maintenance of biodiversity in a community, to the causal structure that supports them. Equally we can identify which populations act to diminish biodiversity. Functional units can be a single population or set of populations weakly acting in unison to create a robust system capacity. In all these cases CR functions describe how these 
complex systems, once specified clearly, are maintained and give us clear instructions which populations threaten these systems.

The invasive species discussed by conservationists are those we have strong evidence for them negatively impacting local populations, like feral pigs. These are the populations that we currently tend to control, and I believe we should continue to do so. We both want the ecosystem services higher levels of biodiversity provide and to preserve biodiversity due to prudential reasons. These prudential reasons will be shared by most rational agents, and thereby, provide a bridge for negotiating the debate over invasive species. As such, there are reasons to eradicate invasive species in the contexts that we most often want to.

\section{Conclusion}

Ecological function cannot do the heavy lifting some have wanted it to do. Ecological systems do not hold together in a way which will permit large scale normative functions, which require replication or self-maintenance. Instead, we see causally connected systems with pockets of functionally arranged populations, be these of the replicating or self-maintaining type. We are, however, left with resources to sort through the causal structure and identify the features we value today as well as those which provide option value for the future. This will go part of the way to providing mediation in these disputes. However, I fear much of the work will have to be done at the level of social and political discussion.

Acknowledgements: First I would like to thank my reviewers for the helpful feedback. The following people, and collectives, provided feedback or reviewed the paper: ANU Philsoc, Carl Brusse, Mark Colyvan, David Frank, Justin Garson, Paul Griffiths and his lab group, Ste Mann, University of Otago Philosophy Department, Kim Sterelny, and probably more. The views expressed in this paper do not reflect on theirs. Work on this paper was supported by an Australian Research Council Discovery Grant (grant number DP170104924). 


\section{Bibliography}

Amundson, R., \& Lauder, G. V. (1994). Function without purpose. Biology and Philosophy, 9(4), 443-469.

Basl, J. (2017). A trilemma for teleological individualism. Synthese, 194(4), 1057-1074.

Basl, J. (2019). The Death of the Ethic of Life. Oxford University Press.

Bastolla, U., Fortuna, M. A., Pascual-García, A., Ferrera, A., Luque, B., \& Bascompte, J. (2009). The architecture of mutualistic networks minimizes competition and increases biodiversity. Nature, 458(7241), 1018.

Booth, A. (2014). Symbiosis, selection, and individuality. Biology \& Philosophy, 29(5), 657-673.

Brown, J. H., \& Sax, D. F. (2004). An essay on some topics concerning invasive species. Austral Ecology, 29(5), 530-536.

Callicott, J. B. (1995). The value of ecosystem health. Environmental values, 4(4), 345-361.

Chew, M. K., \& Laubichler, M. D. (2003). Natural enemies-metaphor or misconception? Science, 301(5629), 52-53.

Clarke, E. (2011). Plant individuality and multilevel selection theory. In B. Calcott \& K. Sterelny (Eds.), The Major Transitions in Evolution Revisited (pp. 227-250). London: MIT Press.

Clavero, M., \& García-Berthou, E. (2005). Invasive species are a leading cause of animal extinctions. Trends in Ecology \& Evolution, 20(3), 110.

Clements, F. E. (1916). Plant succession: an analysis of the development of vegetation. Carnegie Institution of Washington.

Colyvan, M., Linquist, S., Grey, W., Griffiths, P., Odenbaugh, J., \& Possingham, H. (2009). Philosophical issues in ecology: recent trends and future directions. Ecology and Society, 14(2).

Cooper, G. J. (2003). The science of the struggle for existence: on the foundations of ecology. Cambridge University Press.

Chrome, F. H., \& Moore, L. A. (1990). Cassowaries in North-Eastern Queensland-Report of a survey and a review and assessment of their status and conservation and management needs. Wildlife 
Research, 17(4), 369-385.

Cummins, R. (1975). Functional analysis. Journal of Philosophy, (72), 741-765.

Davis, M. A., Chew, M. K., Hobbs, R. J., Lugo, A. E., Ewel, J. J., Vermeij, G. J., ... Carroll, S. P. (2011). Don't judge species on their origins. Nature, 474(7350), 153.

Dawkins, R. (1982). The Extended Phenotype. Oxford: Freeman.

Dupré, J. (1993). The Disorder of Things. Cambridge, MA: Harvard University Press.

Dussault, A. C., \& Bouchard, F. (2017). A persistence enhancing propensity account of ecological function to explain ecosystem evolution. Synthese, 194(4), 1115-1145.

Eliot, C. (2011). The legend of order and chaos: Communities and early community ecology. In K.

DeLaplante, B. Bryson, \& K. Peacock (Eds.), Handbook of the philosophy of ecology (pp. 49107). New York: Elsevier.

Faith, D. P. (1992). Conservation evaluation and phylogenetic diversity. Biological Conservation, 61(1), 1-10.

Finnoff, D., McIntosh, C., Shogren, J. F., Sims, C., \& Warziniack, T. (2010). Invasive species and endogenous risk. Аnnu. Rev. Resour. Econ., 2(1), 77-100.

Garson, J. (2011). Selected effects and causal role functions in the brain: the case for an etiological approach to neuroscience. Biology \& Philosophy, 26(4), 547-565. https://doi.org/10.1007/s10539-011-9262-6

Garson, J. (2017a). A generalized selected effects theory of function. Philosophy of Science, 84(3), $523-543$.

Garson, J. (2017b). How to be a function pluralist. The British Journal for the Philosophy of Science.

Glackin, S. N. (2010). Tolerance and illness: The politics of medical and psychiatric classification. Journal of Medicine and Philosophy, 35(4), 449-465.

Gleason, H. A. (1926). The individualistic concept of the plant association. Bulletin of the Torrey Botanical Club, 7-26.

Godfrey-Smith, P. (1993). Functions: Consensus without unity. Pacific Philosophical Quarterly, 74(3), 196-208.

Godfrey-Smith, P. (2009). Darwinian populations and natural selection. Oxford: Oxford University 
Press.

Godfrey-Smith, P. (2012). Darwinian individuals. In F. Bouchard \& P. Huneman (Eds.), From groups to individuals. (pp. 17-36). Cambridge: MIT Press.

Griesemer, J. R. (2005). The informational gene and the substantial body: On the generalization of evolutionary theory by abstraction. Idealization XII: Correcting the Model. Idealization and Abstraction in the Sciences, 86, 59-115.

Griffiths, P. E. (1993). Functional analysis and proper functions. The British Journal for the Philosophy of Science, 44(3), 409-422.

Grimm, V. (1998). To be, or to be essentially the same: the self-identity of ecological units'. Trends in ecology \& evolution, 13(8), 298-299.

Guimarães Jr, P. R., Galetti, M., \& Jordano, P. (2008). Seed Dispersal Anachronisms: Rethinking the Fruits Extinct Megafauna Ate. PLOS ONE, 3(3), e1745. https://doi.org/10.1371/journal.pone.0001745

Holm, S. (2017). Teleology and biocentrism. Synthese, 194(4), 1075-1087.

Hubbell, S. P. (2001). The Unified Neutral Theory of Biodiversity and Biogeography. Princeton: Princeton University Press.

Janzen, D. H., \& Martin, P. S. (1982). Neotropical anachronisms: the fruits the gomphotheres ate. Science, 215(4528), 19-27.

Jax, K., Jones, C. G., \& Pickett, S. T. (1998). The self-identity of ecological units. Oikos, 253-264.

Jax, K. (2006). Ecological units: definitions and application. The Quarterly Review of Biology, 81(3), $237-258$.

Johnson, L. E. (1991). A morally deep world: An essay on moral significance and environmental ethics. Cambridge: Cambridge University Press.

Kricher, J. (2009). The balance of nature: ecology's enduring myth. Princeton: Princeton University Press.

Kritsky, G. (1991). Darwin's Madagascan hawk moth prediction. American Entomologist, 37(4), 206210.

Lean, C. H. (2017). Biodiversity Realism: Preserving the tree of life. Biology \& Philosophy, 32(6), 
$1083-1103$.

Lean, C. H. (2018). Indexically Structured Ecological Communities. Philosophy of Science, 85(3), $501-522$.

Lean, C., \& Sterelny, K. (2016). Ecological hierarchy and biodiversity. In J. Garson, A. Plutynski, \& S. Sarkar (Eds.), The Routledge handbook of biodiversity. London: Routledge.

Lewis, D. (1971). Counterparts of persons and their bodies. The Journal of Philosophy, 68(7), 203211.

Mace, G. M., Norris, K., \& Fitter, A. H. (2012). Biodiversity and ecosystem services: a multilayered relationship. Trends in ecology \& evolution, 27(1), 19-26.

Mackie, P., \& Jago, M. (2017). Transworld Identity. The Stanford Encyclopedia of Philosophy. Retrieved from https://plato.stanford.edu/entries/identity-transworld/

Maclaurin, J., \& Sterelny, K. (2008). What is biodiversity? Chicago: University of Chicago Press.

McShane, K. (2014). Individualist Biocentrism vs. Holism Revisited. Les ateliers de l'éthique / The Ethics Forum, 9 (2), 130-148. https://doi.org/10.7202/1026682ar

Millikan, R. G. (1984). Language, thought, and other biological categories: New foundations for realism. Cambridge: MIT press.

Millstein, R. L. (Forthcoming) Functions and Functioning in Aldo Leopold's Land Ethic and in Ecology. Philosophy of Science

Moreno, A., \& Mossio, M. (2015). Biological autonomy: A Philosophical and Theoretical Enquiry. Springer.

Mossio, M., Saborido, C., \& Moreno, A. (2009). An organizational account of biological functions. The British Journal for the Philosophy of Science, 60(4), 813-841.

Mossio, M., \& Bich, L. (2017). What makes biological organisation teleological?. Synthese, 194(4), 1089-1114.

Neander, K. (1983). Abnormal psychobiology. Unpublished PhD Thesis, LaTrobe.

Nehring, K., \& Puppe, C. (2002). A theory of diversity. Econometrica, 70(3), 1155-1198.

Nunes-Neto, N., Moreno, A., \& El-Hani, C. N. (2014). Function in ecology: an organizational approach. Biology \& Philosophy, 29(1), 123-141. https://doi.org/10.1007/s10539-013-9398-7 
Odenbaugh, J. (2010). On the very idea of an ecosystem. In A. Hazlett (Ed.), New waves in metaphysics (pp. 240-258). Palgrave Macmillan.

Paine, R. T. (1974). Intertidal community structure. Oecologia, 15(2), 93-120.

Paine, R. T. (1966). Food Web Complexity and Species Diversity. The American Naturalist, 100(910), 65-75. https://doi.org/10.1086/282400

Pearce, F. (2015). The new wild: Why invasive species will be nature's salvation. Icon Books Ltd.

Pimm, S. L. (1991). The balance of nature?: ecological issues in the conservation of species and communities. Chicago: University of Chicago Press.

Post, D. M., Doyle, M. W., Sabo, J. L., \& Finlay, J. C. (2007). The problem of boundaries in defining ecosystems: a potential landmine for uniting geomorphology and ecology. Geomorphology, 89(1), 111-126.

Raffles, H. (2011) Mother Nature's melting pot. New York Times (2 April 2011): WK12

Rezende, E. L., Jordano, P., \& Bascompte, J. (2007). Effects of phenotypic complementarity and phylogeny on the nested structure of mutualistic networks. Oikos, 116(11), 1919-1929.

Ricklefs, R. E. (2005). Phylogenetic perspectives on patterns of regional and local species richness. In E. Bermingham, C. Dick, \& C. C. Moritz (Eds.), Rainforest: Past, Present and Future (pp. 16-40). Chicago: University of Chicago Press.

Rolston III, H. (1988). Environmental ethics. Philadelphia: Temple University Press.

Saborido, C., Mossio, M., \& Moreno, A. (2011). Biological organization and cross-generation functions. The British Journal for the Philosophy of Science, 62(3), 583-606.

Sagoff, M. (1984). Animal liberation and environmental ethics: Bad marriage, quick divorce. Osgoode Hall Law Journal, 22, 297-307.

Sagoff, M. (2005). Do non-native species threaten the natural environment? Journal of Agricultural and Environmental Ethics, 18(3), 215-236.

Sagoff, M. (2019). When is it co-evolution? A reply to Steen and co-authors. Biology \& Philosophy, $34(10), 1-19$

Sandler, R. (2007). Character and environment: A virtue-oriented approach to environmental ethics. New York: Columbia University Press. 
Sarkar, S. (2012). Environmental philosophy: from theory to practice. John Wiley \& Sons

Simberloff (2015) Nature's nature and the place of non-native species. Current biology 25, R585R599

Simberloff, D., Martin, J.-L., Genovesi, P., Maris, V., Wardle, D. A., Aronson, J., .. Pascal, M. (2013). Impacts of biological invasions: what's what and the way forward. Trends in Ecology \& Evolution, 28(1), 58-66.

Singer, P. (1975). Animal liberation. Random House.

Skillings, D. (2016). Holobionts and the ecology of organisms: Multi-species communities or integrated individuals? Biology \& Philosophy, 31(6), 875-892.

Soulé, M. E. (1985). What Is Conservation Biology? BioScience, 35(11), 727-734. https://doi.org/10.2307/1310054

Sterelny, K. (2005). The elusive synthesis. In K. Cuddington \& B. Beisner (Eds.), Ecological Paradigms Lost: Routes of Theory Change (Vol. 2, pp. 311-329). Elsevier.

Sterelny, K. (2006). Local ecological communities. Philosophy of Science, 73(2), 215-231.

Stocker, G. C., \& Irvine, A. K. (1983). Seed dispersal by cassowaries (Casuarius casuarius) in North Queensland's rainforests. Biotropica, 170-176.

Sullivan, S. (1996). Guest editorial: towards a non-equilibrium ecology: perspectives from an arid land. Journal of Biogeography, 23(1), 1-5.

Taylor, P. W. (1989). Respect for nature. Princeton: Princeton University Press

Thompson, K. (2014) Where do camels belong? the story and science of invasive species. Profile Books, London

Varner, G. E. (1998). In nature's interests?. Oxford University Press.

Wakefield, J. C. (1992). Disorder as harmful dysfunction: a conceptual critique of DSM-III-R's definition of mental disorder. Psychological Review, 99(2), 232.

Winograd, N. J. (2013) Biological xenophobia: the environmental movement's war on Nature. Huffington Post: the blog, 6 June 2013

Young, A. M., \& Larson, B. M. (2011). Clarifying debates in invasion biology: a survey of invasion biologists. Environmental Research, 111(7), 893-898. 
